\title{
Can the onset of orbital cancer be the result of a prosthetic eye?
}

\author{
L'insorgenza di un tumore orbitario può risultare dall'utilizzo di una protesi oculare? \\ A. CROCE, V. MASTRONARDI, M. LAUS, E. FESTA KOTELNIKOVA \\ ENT Department, University "G. d'Annunzio" of Chieti-Pescara, Hospital "SS Annunziata", Chieti, Italy
}

\section{SUMMARY}

Orbital exenteration is a disfiguring procedure performed for unresponsive orbital infections and control of recurrent benign tumours and malignancies arising from the eyelids (basal cell carcinoma, squamous cell carcinoma, conjunctival malignant melanoma), lachrymal glands (adenoid cystic carcinoma) or surrounding sinuses. In extremely rare cases the use of a prosthetic eye after enucleation can lead to anophthalmic socket tumours. We report the case of a 54-year-old man who had left eye enucleation due to recurring events of retinal detachment and who developed an invasive fast growing epidermoid carcinoma 30 years later. We review the literature to evaluate the rarity of the occurrence, time of onset after enucleation, treatments and outcomes. Our case illustrates the management of the pathology and emphasises the necessity of careful examination of the anophthalmic socket and the ocular prosthesis to identify any irregularities or damage on its surface even after exenteration that is not performed for malignant disease. Long-term follow up is necessary because this tumour could occur at long time periods after enucleation.

KEY WORDS: Orbital exenteration • Eyelid carcinoma • Anophthalmic socket

\section{RIASSUNTO}

L'exenteratio orbitae è un intervento deturpante che si pratica in caso di infezioni orbitarie non responsive a terapia medica e in caso di tumori benigni ricorrenti e tumori maligni che insorgono dalle palpebre (carcinoma basocellulare, carcinoma squamocellulare, melanoma maligno della congiuntiva), dalle ghiandole lacrimali (carcinoma adenoideo cistico) o dalle strutture circostanti. In casi estremamente rari l'uso di protesi oculari dopo l'enucleazione può causare l'insorgenza di tumori orbitari. In questo articolo riportiamo il caso di un uomo di 54 anni che è stato sottoposto ad enucleazione dell'occhio sinistro in seguito a ricorrenti distacchi di retina e che ha sviluppato, solo 30 anni dopo, un carcinoma epidermoidale infiltrante a rapida crescita. Abbiamo esaminato gli articoli in letteratura per valutare la rarità di tale occorrenza, i tempi d'insorgenza in seguito all'enucleazione, i trattamenti e i risultati. Il nostro caso illustra il trattamento della patologia ed enfatizza la necessità di un attento esame della cavità orbitaria e della protesi oculare per identificare anche le irregolarità e i primi danni sulla superficie orbitaria anche nei casi in cui l'exenteratio orbitae è stata eseguita per patologie benigne. Il nostro caso dimostra che il follow-up a lungo termine è fondamentale perché il tumore può insorgere a lunga distanza dopo l'enucleazione.

PAROLE CHIAVE: Exenteratio orbitae $\bullet$ Carcinoma della palpebra $\bullet$ Cavità orbitaria

Acta Otorhinolaryngol Ital 2017;37:519-522

\section{Introduction}

Orbital exenteration is a procedure performed for unresponsive orbital infections as well as local control of recurrent benign tumours and malignancies arising from the eyelids (basal cell carcinoma, squamous cell carcinoma, conjunctival malignant melanoma), lachrymal glands (adenoid cystic carcinoma), or the surrounding sinuses.

In 1971 Meyer and Zaoli classified the exenteration procedure into four groups ${ }^{1}$ :

- Type I: the palpebral skin and the conjunctiva are left intact;

- Type II: only the palpebral skin is left intact;

- Type III: both eyelids are removed with orbital contents;
- Type IV: the eyeball, eyelids and appendages of the eye are removed together with the involved bone structures.

From 1999, according to Mouriaux F et al. ${ }^{2}$, orbital exenterations may be subdivided into three categories:

- sub-total: orbital tissues are partially removed with sacrifice of the globe;

- total: removal of all tissues within the orbit including the globe and periorbital;

- extended: resection of adjacent bone.

A simpler classification was proposed by Yeatts $(2005)^{3}$, who divided exenterations in only two categories:

- subtotal: partial removal of orbital tissues;

- total exenteration: removal of the entire orbital content. 
Orbital exenteration is a disfiguring procedure but if combined with immediate reconstruction treatment, it improves the quality of life of patients ${ }^{4}$.

To reconstruct an exenteration defect, there are a large number of options: spontaneous granulation (often takes several months but provides better colour), skin grafts (the process is faster), temporalis muscle flap associated with skin graft, cervicofacial flap, temporoparietal fascial flap, frontal flap, free tissue transfer using the rectus abdominis, latissimus dorsi, radial forearm, lateral arm and anterolateral thigh flap. Reconstruction methods by free tissue transfer are often used when the exenteration is associated with maxillectomy. Attempts have been made with a fibular osteocutaneous flap, an iliac crest internal oblique free flap and latissimus dorsi-scapular/parascapular flap. Orbital exenteration and reconstruction with prosthesis can lead to other pathologies on rare occasions, as we demonstrate in the following case.

\section{Description of clinical case}

A 54-year-old man presented to the ENT Clinic of SS Annunziata of Chieti with a fast growing mass from his left orbit that completely occluding the left eye socket (Fig. 1-A).

From the patient's history, it was noticed that the left eye had been enucleated 30 years before, due to recurring events of retinal detachment with complications that made left eye exenteration necessary. Since that time he had used a smooth ocular prosthesis made of artificial resin in the anophthalmic socket (Fig. 1-B). He referred he had no discomfort, irritation, or discharge in the eye socket or need for maintenance of the prosthesis over the years.

Apart from enucleation, the patient had an unremarkable medical history and no family history of malignancy.

In 2014 the patient had surgery for right retinal detachment. At that time no difficulty in wearing the left eye prosthesis was noticed.

At admission time, the patient had a large mass covering the whole left ocular surface with several bleeding sites on it. The mass was reported to be growing fast in the previous few months before presentation at our eye clinic. On examination, the mass was arising from his left lower eyelid, and cilia were present in upper left eyelid. Regional lymph nodes were not palpable.

Gadolinium-enhanced magnetic resonance imaging revealed a contrast enhanced mass occupying the anterior part of the left orbit and spreading outside, measuring 3.6 $\mathrm{cm} \times 2 \mathrm{~cm} \times 2 \mathrm{~cm}$. There were no signs of invasion of the surrounding bony orbit.

A biopsy was performed and histological examination revealed invasive, keratinised, moderately differentiated epidermoid carcinoma.

Surgical treatment consisted of excision of the entire tumour mass, removing the orbital content and the left lower eyelid (Fig. 1-C). The eye socket was reconstructed using a Thiersch skin graft taken from the abdomen of the patient (Fig. 1-D).

The mass measured 5.5 x 4.8 × $3 \mathrm{~cm}$. Histological examination confirmed invasive, ulcerated, keratinised, moderately differentiated epidermoid carcinoma and margins free of disease.

The patient recovered well. After 6 months free of surgical complications, he started the procedure to fit an epithesis.

\section{Discussion}

Malignant tumours of the orbit and the orbitomaxillary region constitute $4-8 \%$ of head and neck malignancies. In particular, eyelid malignancies represent approximately $5 \%$ to $10 \%$ of all skin cancers and more than $90 \%$ of all ophthalmic tumours. Incidence studies report that basal cell carcinoma is the most common malignant ocular neoplasia, counting for $80-90 \%$ of cases, followed by squamous cell carcinoma (5-10\%), retinoblastoma, sebaceous gland carcinoma, malignant melanoma ${ }^{4}$, rhabdomyosarcoma and Merckel cell carcinoma, even if it is demonstrated that the histopathological spectrum and relative frequencies vary markedly among different countries. The regional differences may be due to different skin types (high rate in fair-skinned populations), sunlight exposure and disease awareness.

Ultraviolet light exposure, smocking, genetic mutation, radiation, HPV type 16 and 18 infection, HIV infection and chronic inflammation of the ocular surface are the main risk factors for ocular surface epithelial neoplasia. Although sun exposure is widely accepted as a risk factor for developing basal cell carcinoma, squamous cell carcinoma and melanoma, the mechanism of carcinogenesis in these lesions is not clear.

Basal cell carcinoma is a neoplasm of epithelial origin caused mainly by ultraviolet radiation.

Squamous neoplasms can involve the conjunctiva or the cornea individually, but they probably arise from the corneal epithelial stem cells of the limbal region, which represent a transitional zone between the conjunctival epithelium and the stratified squamous corneal epithelium, and then extend across the limbus to involve the adjacent cornea.

A malignant tumour growing in an anophthalmic orbit, without a history of previous malignant tumours, is extremely rare. A review of literature identified only a few cases of carcinoma developing in an anophthalmic socket. Espana et al., in 2011, reported a detailed review of eight previous published cases reporting some similar characteristics ${ }^{5}$.

Like our case, all patients were male and all developed a squamous cell carcinoma of the eyelid in an average time of 44.8 years after prosthesis use. The present case, however, would represent the shortest interval post-exentera- 


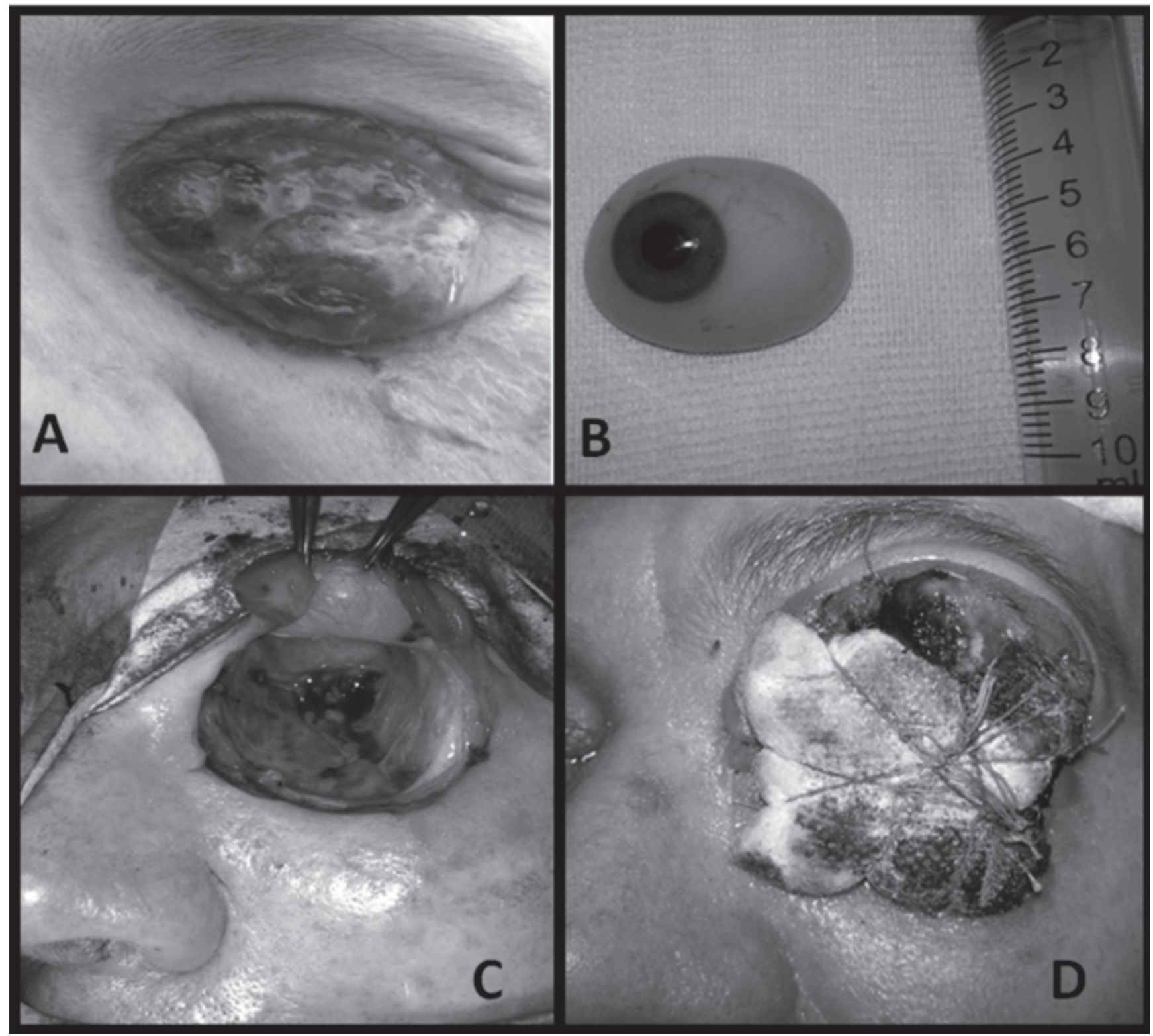

Fig. 1. A 54-year-old man presented in ENT Clinic of SS Annunziata of Chieti with a mass fast growing from his left orbit and completely occluding the left eye socket (Fig. 1-A). For 30 years he had used a smooth ocular prosthesis made of artificial resin in the anophthalmic socket (Figure 1-B). The surgical treatment consisted of excision of the entire tumour mass removing the orbital content and the left lower eyelid (Fig. 1-C). The eye socket was reconstructed using a Thiersch skin graft taken from the abdomen of the patient (Fig. 1-D).

tion reported, at 30 years after exenteration and diagnosis of squamous cell carcinoma. The upper eyelid was, according to Espana review, the most common site, while in our case the lower eyelid was involved ${ }^{5}$. Our patient also presented an advanced local stage of the tumour at diagnosis with a large, rapidly-growing cauliflower-like mass covering the entire ocular surface, but without regional and distant metastasis.

Previous studies hypothesised that chronic irritation from wearing an eye prosthesis for more than 40 years was suspected to be associated with the development of conjunctival squamous cell carcinoma and melanoma. Our patient did not present any signs or symptoms of prosthetic dis- comfort before tumour growth, and his ocular prosthesis did not present any irregularities or damage that could lead to chronic inflammation. Despite this, after 30 years of wearing a good-fitting prosthesis a squamous cell ocular carcinoma developed in an anophthalmic socket. Kim et al. (2008) demonstrated that squamous metaplasia with decreased goblet cell density and increased nucleus-tocytoplasm ratio can occur in anophthalmic sockets without any particular aspects of prosthesis care ${ }^{6}$. There were probably other risk factors involved that remain unknown in this carcinogenesis. For example, a viral origin cannot be excluded in the pathogenic mechanism because we did not perform molecular testing to identify a viral cause. 
Our patient is a rare case of ocular surface squamous neoplasia that developed in an anophthalmic socket 30 years after exenteration not performed for malignant disease. It arose from the lower palpebral conjunctival surface as a large mass occupying all the ocular surface. We performed an exenteration revision. Our patient has exceeded the postoperative period without any complications and currently rehabilitation is planned with a new aesthetic orbital prosthesis considering his young age. In the literature it is reported that only $10.8 \%$ of patients received ocular prosthetic rehabilitation after surgical treatment, which is associated with lower age and enucleation surgery ${ }^{7}$.

The onset of discharge, swelling, recent poor fitting of prosthesis, or a palpable orbital mass in a patient wearing an ocular prosthesis for many years should suggest a possible malignant neoplasm. Accordingly, careful ophthalmic examination of the anophthalmic socket and the ocular prosthesis should be performed to identify possible irregularities or damages on its surface. Long-term follow up is necessary because this tumour can occur after long time period following enucleation.

\section{Acknowledgements}

The authors would like to thank the patient for providing consent to use his photograph in this article.

\section{References}

1 Radici M, Bicciolo G, Palma O, et al. Il massicciofaciale. In: De Campora E, Marzetti F, editors. La chirurgia oncologica della testa e del collo. Pisa, Pacini Editore; 1996. ,p. 345-381.

2 Mouriaux F, Martinot V, Pellerin P, et al. Survival after malignant tumors of the orbit and periorbit treated by exenteration. Acta Ophthalmol Scand 1999;77:326-30.

3 Yeatts RP. The esthetics of orbital exenteration. Am J Ophthalmol 2005;139:152-3.

4 Croce A, Moretti A, D'Agostino L, et al. Orbital exenteration in elderly patients: personal experience. Acta Otorhinolaryngol Ital 2008;28:193-9.

5 Espana EM, Levine M, Schoenfield L, et al. Ocular surface squamous neoplasia in an anophthalmic socket 60 years after enucleation. Surv Ophthalmol 2011;56:539-43.

6 Kim JH, Lee MJ, Choung HK, et al. Conjunctival cytologic features in anophthalmic patients wearing an ocular prosthesis. Ophthal Plast Reconstr Surg 2008;24:290-5.

7 Sirianni D, Rodriguez Leles C, Mendonça EF. A 12-years retrospective survey of management of patients with malignant neoplasm in the orbital cavity in a Brazilian cancer hospital. Open Dent J 2013;7:140-5. 